\title{
Research on Optimization of Time Concept and Management Strategy of Post-90s University Students
}

\author{
Yuhang Wang \\ School of International Studies, University of International Business and Economics, China \\ aYuhang012@163.com
}

Keywords: University students, time concept, management strategy

\begin{abstract}
The time concept of Post-90s university students is established on their recognition of characteristics of learning in university. This concept shows their pursuit of what is better for learning as the pursuit of value. They construct their individual time framework in accordance with public and institutional time framework. This is the product of the interaction between university students and the university institution and the inevitable consequence of pursuing self-improvement. The optimization of university students' time management strategy requires the enhancement of sense of morality in time management, the enforcement of their recognition of the nature of learning in university, the expansion of learning time and full utilization of learning elements in liberal time.
\end{abstract}

\section{Introduction}

Time concept of college students not only is an important part of learning ability for college students and is an important factor of influencing learning efficiency, but also is the basic part composing learning rules of college students, which reveals the understanding of university students on the nature and difference between learning activities and extracurricular activities. Time structure embodies the time allocation strategy of college students for different activities, which shapes diversified university life. Research time concept and structure has great significance for understanding learning awareness and learning capability of college students, improving and innovating management and promoting college students to effective use time.

Most domestic researches about time of college students focus on time management tendency, efficacy and psychological state influence. The former considers that half of college students have great time management tendency, and some students have the phenomenon of severely wasting time [1]. And the former uses management theory to propose the decision of improving time management, and introduces the variables including college level, confidence level and sex into the research [2]. The latter realizes that time management plays the prediction role in psychological pressure, self-efficacy and capability of adapting to society of college students [30, which not only has evident explanatory power on learning satisfaction[4], but also has positive relationship with achievement motivation [5].

\section{Research Design and Concept Definition}

(1) Research design. The research uses the norm form of quantitative research, and applies survey study method. And the implementation time is May 2011. The research samples are 2070 students in University of International Business and Economics, and the number of samples is 1050. The research samples are from International Business School, Economics and Finance School, English College, Insurance College and Law College, and 1050 questionnaires were issued, in which 860 effective questionnaires are recycled, and the recovery rate is $82 \%$. There were 655 girls and 205 boys. There were 326 art students and 417 science students, and 117 students without choosing art and science. In order to effectively formulate questionnaires, in the process of modifying and formulating questionnaires, the research group makes deep interview on 3 freshmen from the above colleges. The interview is about the indexes of survey questionnaires. The information achieved from deep interview plays a supplementary role in analyzing and investigating data. 
Concept definition. In order to achieve real first-hand materials, the research group makes questionnaires by themselves. And the questionnaires don't involve the time unit of semester. And the involved concept definition is as follows.

1. Source of learning motivation. The research defines that there are three sources of learning motivation of college students. The first source is professional identity which enhances professional learning to bring preconceived vocational perspective. The second source is professional identity vagueness, which depends on course requirements and examination pressure to learn. The third source is professional identity deficiency, which changes the pressure into learning motivation.

2. Learning time and free time. The research considers that the life time of college students consists of learning time and free time. Learning time means the total time of psychology and behavior of college students in preparation and suspension of learning activities. Free time means the total time of psychology and behavior of college students in preparation and suspension of social communication and entertainment.

3. Learning intervals. For learning time, the time interval between two learning activities is learning interval. The functions include rest, surfing on internet, washing clothes and shopping, processing the work of student union and class, making learning reflection and summary, and achieving innovation idea and inspiration.

\section{Research Results}

(1) $38.5 \%$ of surveyed students have certain understanding on speciality of time concept and time structure. And 52.3\% of surveyed students lack of consciousness and scientific cognition. The research indicates that $90.8 \%$ of surveyed students consider that there is great difference between time concept of university student group and career professionals, in which $52.3 \%$ of students consider that there is difference for time concept, and career professionals lack of understanding on time concept. 38.5\% of students consider that career professionals should use 8 hours as the time framework, and college students use time course as time framework, which is a basic factor of making time consciousness of college students and other social groups different.

(2) The source of learning motivation of university students is diversified. The learning motivation of $34 \%$ of surveyed students is professional identity, and that of $51 \%$ of surveyed students is course and examination pressure. The research indicates that professional identity of 34\% surveyed students is high, which means to be optimistic for predicted vocational outlook. And learning motivation is from inherent pursuit. The professional identity of $51 \%$ of surveyed students is fuzzy, and the learning motivation is from external environment influence. $9 \%$ of students transform pressure into learning motivation in order to change dissatisfying status. The learning motivation includes inherent pursuit and external environmental influence. From the perspective of sex difference, the learning motivation of $22 \%$ of boys and $37 \%$ of girls is from inherent pursuit, and the learning motivation of $63 \%$ of boys and $48 \%$ girls is from external environmental influence, and the learning motivation of $9 \%$ of boys and $9 \%$ of girls includes inherent pursuit and external environmental influence. We can see that the learning motivation of students focuses on external environmental influence. Selecting course and examination pressure is the learning motivation of half of students, and appraisal has evident influence on learning process of students.So professional identity of girls is higher than that of boys.

(3) $63.1 \%$ of surveyed students have clear definition on learning time and free time, and consider that learning time include weekends and learning activities time, in which the learning time of girls is more than that of boys. The data indicates that $40.9 \%$ of surveyed students consider that weekends are learning time besides the time from Monday to Friday. 22.2\% of students think that it is the learning time from Sunday evening to Friday morning, the reason for which is that Sunday evening is the preparation time of learning activities on Monday, and Friday afternoon is the preparation time of free activities on weekends. $20.7 \%$ of students consider that only the time of taking class is learning time, and the other time is free time. Only $14.2 \%$ of surveyed students are difficult to identify learning time and free time, and they think that the time at school is learning time. From the perspective of sex, $46 \%$ of girls think that weekends are learning time besides the 
time from Monday to Friday, so doe $29 \%$ of boys. $17 \%$ of girls think that only the time of taking class is learning time, so do $34 \%$ of boys. We can get that the learning time of girls is more than that of boys. Half of surveyed students process trivial affairs at learning intervals. And $19.2 \%$ and $17.7 \%$ of students use learning intervals for learning and processing learning affairs. The data shows that $50 \%$ of surveyed students use learning time to arrange daily affairs including rest, surfing on internet, washing clothes and shopping. $19.2 \%$ of students study designedly. $17.7 \%$ of students processing learning affairs. There are $22 \%$ of boys processing learning affairs at learning intervals, which is $6 \%$ higher than that of girls. There are $23 \%$ of girls making learning summary and reflection at learning intervals to achieve innovative idea, which is $9 \%$ higher than that of boys. Therefore, sex difference of applying learning intervals is not evident.

(4) Nearly $70 \%$ of surveyed students tend to consider that social communication at learning time is suspension of learning. Learning activities at free time include social component.The research indicates that $69.7 \%$ of surveyed students think that mental impression of watching film on Wednesday evening and on Saturday evening is different. And the attitude of boys and girls for the problem is different. Only $50 \%$ of boys have the opinion, and $76 \%$ of girls have the opinion. $68.5 \%$ of surveyed students think that the mental impression of group discussion on Wednesday evening and on Saturday evening is different, which means that the group discussion on Wednesday evening is learning, and that on Saturday evening is social communication. Above all, we think that the time concept of post-90 students use week as cyclic unit. Thee are three time frameworks. It is general that it is working time from Monday to Friday, and Saturday and Sunday is official holiday. The second framework is system time. It is based on public time, and includes school time and out-of-class study. It is general that school time is in working time, and out-of-class study includes official holiday and the time without classes in working time. The third framework is individual time established based on condition of college students. It is based on the former frameworks. Therefore, under three time frameworks, the learning time of post-90 college students covers learning activities in school time, social activities in working time and learning activities. And the real free time is the time of social activities in official holiday (as shown in Table 1).

Table 1 College students three time frame and its activity categories

\begin{tabular}{l|l|l|l|l}
\hline \multirow{2}{*}{ public time } & \multicolumn{2}{|c|}{ working time (from Monday to Friday) } & \multicolumn{2}{c}{ general holiday time (Saturday and Sunday) } \\
\hline system time & school time & \multicolumn{2}{c}{ out-of-class time } & free time \\
\hline individual time & \multicolumn{2}{|c}{ learning time } & rearning activities \\
activity category & $\begin{array}{l}\text { learning } \\
\text { activities }\end{array}$ & $\begin{array}{c}\text { social activities } \\
\text { (suspension of learning) }\end{array}$ & $\begin{array}{l}\text { social activities } \\
\text { (consistence of learning) }\end{array}$ \\
\hline
\end{tabular}




\section{Theoretical Observation}

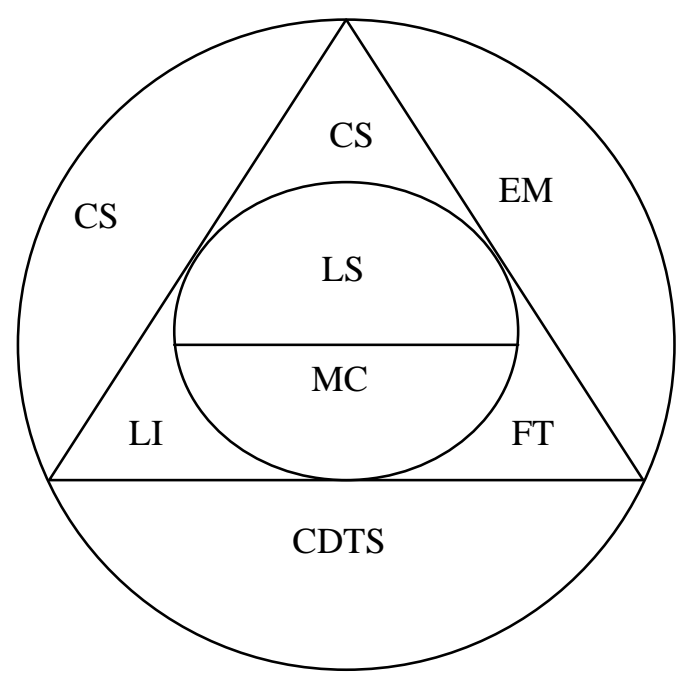

CS: course system, LT: learning time,LS: learning consciousness, EM: evaluation mode $\mathrm{MC}$ : moral consciousness, LI: learning intervals FT: free time CDTS: concept difference of teachers and students

Fig.1 Components of time concept and structure of college students

Conclusion and Management Strategy Optimization. we can clearly get that under the condition of difference of learning and moral consciousness, and under the influence of external course system, evaluation mode and concept of students and teachers, college students have great difference for the proportion and distribution of learning time, learning intervals and free time, which reflects the basic relationship between college students and learning environment interaction, as shown in Fig. 1.

\section{Conclusion}

Learning is the core of time concept of college students, and learning time and free time is the major unit of time structure. Learning of college students goes through learning time and free time. Under the course system and evaluation mode of foreign language colleges, the girls are easy to achieve learning motivation, and has more rational time concept and structure. The time concept of excellent students is moral pressing and conscious.

Measures of optimizing time management strategy of college students . Scientific time concept is from perceiving the nature of learning in colleges, extending learning time combined with the condition of college students., fully excavating learning functions of free time., promoting moral sense of managing time..

\section{Acknowledgment}

This paper is a Key project research of Humanities and Social Sciences "On the new characteristics of College Students' academic development and values under the influence of new media ” ofUniversity of International Business and Economics (11JYX01).

\section{References}

[1] Wu Yingfeng, Status and countermeasures of time management of college students [J], Science and Technology Association Forum, 2007(4)309-310.

[2] Zhang Tian, Xie Yuhan, Comparison of time management tendency of college students with different confidence levels[J], China Health Psychology Journal, 2004(16):615-618. 